\title{
O DiREITO DE PROPRIEDADE E JUSTIÇA
}

THADEU WEBER ${ }^{\dagger}$

RESUMO: O objetivo do texto é justificar o direito de propriedade como direito fundamental individual e explicitar seu conteúdo. Locke, Hegel e Rawls são referidos como fontes históricas consagradas para esse intuito. Locke, pela tese de que o trabalho fundamenta a propriedade; Hegel, pela estreita vinculação entre propriedade e liberdade; Rawls, por ter enumerado a propriedade entre os direitos fundamentais que compõem o primeiro princípio de sua concepção política de justiça. Justifica-se, com isso, ser o direito de propriedade um elemento constitucional essencial.

Palavras-Chave: Direitos Fundamentais; Propriedade; Justiça; Liberdade; Trabalho.

ABSTRACT: My aim in this paper is to justify the right of property as a fundamental right and to make its content explicit. Locke, Hegel, and Rawls are referred as established historical sources for this matter. Locke, with the thesis according to which labor is a foundation of property; Hegel, with the close bound between property and freedom; and Rawls, for having accounted freedom as a fundamental right that composes the first principle of his political conception of justice. I argue, therefore, that the right of property is an essential constitutional element.

KEYWORDS: Fundamental Rights; Property; Justice; Freedom; Work.

\footnotetext{
† Doutor em Filosofia pela Universidade Federal do Rio Grande do Sul. Professor nos Programa de Pós-Graduação em Direito e em Filosofia. Pesquisador nas áreas de Teorias da Justiça e Filosofia do Direito.
} 


\section{SUMÁRIO:}

I. INTRODUÇÃO .........................................................................................801

II. Propriedade e Trabalho (LOCKE) ...............................................801

III. DIREITO DE PROPRIEDADE E LIBERDADE (HEGEL) ..........................807

IV. DireITO DE Propriedade E JuSTIÇA (RAWLS) ................................809

V. CONSIDERAÇões Finais:

O DiREITO DE PROPRIEDAde E JUSTIÇA..............................................813

VI. REFERÊNCIAS..........................................................................................815

\section{TABLE OF CONTENTS:}

I. INTRODUCTION ......................................................................................801

II. PROPERTY AND WORK (LOCKE) ........................................................801

III. Property Right AND Liberty (Hegel) ..........................................807

IV. PROPERTY Right AND JUSTICE (RAWLS) ........................................809

V. Final Considerations: the Proerty Right AND Justice......813

VI. REFERENCES ...........................................................................................815 


\section{INTRODUÇÃO}

O direito de propriedade deve ou não ser um direito fundamental? Como justifica-lo? Qual é, propriamente, seu conteúdo? Envolve o direito de herança e o direito de possuir meios de produção? Essas questões sempre foram objeto de muita controvérsia. Conflitos de toda ordem resultam na efetivação desse direito.

O objetivo desse estudo é justificar o direito de propriedade como direito fundamental e, com isso, sustentar que deve integrar o conjunto dos "elementos constitucionais essenciais". Trata-se, por um lado, de uma conquista da história e, por outro, de um renovado acordo nas democracias deliberativas. Sistemas políticos que o aboliram fracassaram. O fim da União Soviética e a queda do Muro de Berlim são exemplos disso.

O tema, obviamente, não é novo e os tratados sobre o assunto são inúmeros. Autores, com as mais diferentes posições, já se ocuparam desse debate. O propósito, aqui, é se valer de algumas dessas abordagens que em muito contribuíram para a justificação desse direito, fazendo com que constasse das constituições democráticas mais bem-sucedidas no mundo contemporâneo. Nunca é demais voltar ao tema, sobretudo no contexto em que se discute qual é propriamente a função desse direito e que conteúdo inclui.

A Constituição de 1988 em seu artigo 50, inciso XXII, consagra o direito de propriedade e no inciso posterior aduz sua função social. Sua justificação está ligada ao princípio da dignidade humana. O debate sobre o que compõe o mínimo existencial situa-se nesse contexto. Sobre seu conteúdo, no entanto, sobretudo no que se refere à função social, há muita controvérsia. O que são propriamente terras produtivas? Que índices de produtividade deveriam ser adotados? Qual é a relação entre valor e trabalho? Essas questões não estão respondidas e são de difícil acordo. $\mathrm{O}$ que se pode dizer, sem dúvida, é que o direito de propriedade é uma das formas de concretização do princípio de dignidade humana e este, por sua vez, é um dos fundamentos da Carta Magna brasileira.

A resposta às referidas questões envolve, pelo menos, dois temas centrais: o problema da justificação do direito de propriedade e a definição de seu conteúdo. Locke, Hegel e Rawls têm excelentes contribuições.

\section{Propriedade e Trabalho (Locke)}

O direito de propriedade constitui uma das bases das ideias liberais, 
defendidas por John Locke, em seu Segundo Tratado Sobre o Governo Civil. ${ }^{1}$ Trata, inicialmente, de explicitar os pressupostos epistemológicos daquelas ideias. Demonstrou em seu Ensaio Acerca do Entendimento Humano $^{2}$ que não existem princípios teóricos nem princípios práticos inatos e que, portanto, todo conhecimento é adquirido. Inata é, somente, a capacidade. ${ }^{3}$ Ora, se não existem ideias e princípios práticos inatos é porque também não existe poder político que possa ser considerado inato. Também este é adquirido. Aliás, o poder é de todos. Isso indica que o direito de propriedade, embora seja natural, também não é inato. Ser natural significa que é anterior ao pacto e independente dele. Se não é inato, é porque deve ser efetivado pelo trabalho. Ninguém nasce proprietário, mas apenas com o direito de sê-lo. Ter um direito, neste caso, é condição necessária, mas não suficiente para sua efetivação. Propriedade e trabalho constituem, pois, o binômio basilar do Estado moderno liberal. Para chegar a esta conclusão, foi fundamental apresentar argumentos sólidos contra a existência de ideias inatas e mostrar sua origem empírica. Havia a necessidade de demonstrar que quaisquer princípios, ainda que evidentes, podiam ser questionados. A dificuldade de compreendê-los não os provaria inatos. A admissão de princípios inatos facilitaria em muito a crença de que tais princípios devem ser aceitos sem exame posterior. $\mathrm{O}$ dogmatismo seria o caminho natural. Governar os povos a partir disso era uma tarefa enormemente facilitada. A obra de Locke é um ataque frontal ao inatismo e ao dogmatismo, mas não ao direito natural.

A tese de que o trabalho é o fundamento da propriedade representa o argumento central de justificação do direito de propriedade como inerente a toda pessoa. A natureza deu tudo em comum ao homem, o trabalho o fez merecedor de exclusividade ${ }^{4}$. O pacto, isto é, o Estado,

${ }^{1}$ LOCKE, John. Carta acerca da tolerância: Segundo tratado sobre o governo; Ensaio acerca do entendimento humano. $2^{\mathrm{a}}$ ed. Trad. Anoar Aiex e E. Jacy Monteiro. São Paulo, SP: Abril Cultural, 1978.

2 LOCKE, John. Carta acerca da tolerância: Segundo tratado sobre o governo; Ensaio acerca do entendimento humano. $2^{a}$ ed. Trad. Anoar Aiex e E. Jacy Monteiro. São Paulo, SP: Abril Cultural, 1978.

${ }^{3}$ LOCKE, John. Carta acerca da tolerância: Segundo tratado sobre o governo; Ensaio acerca do entendimento humano. $2^{\mathrm{a}}$ ed. Trad. Anoar Aiex e E. Jacy Monteiro. São Paulo, SP: Abril Cultural, 1978, p. 145.

4 Tese completamente oposta a esta é defendida por Proudhon, em sua obra O que é Propriedade? Afirma o autor, no capítulo III: "o trabalho não tem, por si próprio, 
nasce do desejo de conservar os direitos naturais, tais como a vida e a propriedade. Ao definir poder político, Locke é enfático ao afirmar que ele diz respeito ao "direito de fazer leis com pena de morte e, consequentemente, todas as penalidades menores para regular e preservar a propriedade"..$^{5}$ Esse poder não é inato, mas nasce do pacto entre os homens. E o Estado origina-se da expressa vontade da conservação dos direitos fundamentais naturais, entre os quais estão a vida e a propriedade. No Segundo Tratado, Locke é ainda mais explícito quanto à proteção à propriedade: "O objetivo grande e principal, portanto, da união dos homens em comunidade, colocando-se eles sob governo, é a preservação da propriedade" . ${ }^{6}$ Para Macpherson é a partir desse intuito "que é tirada a maioria das conclusões de Locke sobre os poderes e limites da sociedade e do governo civis". ${ }^{7}$

É extremamente elucidativa a tese do empirista, expressa no Segundo Tratado, de que o seu intuito é "mostrar que os homens podem chegar a ter uma propriedade [...], e tal sem qualquer pacto expresso entre todos os membros da comunidade". ${ }^{8}$ Observa-se claramente que a propriedade não é um direito inato, mas ao contrário do que sustenta Hobbes ${ }^{9}$, é um direito natural que antecede os governos civis e que precisa ser efetivado. É um direito que independe de consentimento. Não é, pois, objeto de pacto. "Chegar a ter propriedade" significa através do trabalho. Mas porque o resultado do meu trabalho me pertence? A resposta é deveras contundente: porque eu tenho a propriedade de minha própria pessoa.

nenhum poder de apropriação sobre as coisas da natureza". PROUDHON, PierreJoseph. O que é a propriedade? Lisboa: Editorial Estampa, 1971, p. 91.

${ }^{5}$ LOCKE, John. Carta acerca da tolerância: Segundo tratado sobre o governo; Ensaio acerca do entendimento humano. $2^{\mathrm{a}}$ ed. Trad. Anoar Aiex e E. Jacy Monteiro. São Paulo, SP: Abril Cultural, 1978, p. 34.

${ }^{6}$ LOCKE, John. Carta acerca da tolerância: Segundo tratado sobre o governo; Ensaio acerca do entendimento humano. $2^{\underline{a}}$ ed. Trad. Anoar Aiex e E. Jacy Monteiro. São Paulo, SP: Abril Cultural, 1978, p. 82.

${ }^{7}$ MACPHERSON, Crawford Brough. A Teoria Política do Individualismo

Possessivo: de Hobbes até Locke. Trad. Nelson Dantas. Rio de Janeiro, RJ: Paz e Terra, 1979, p. 209.

${ }^{8}$ LOCKE, John. Carta acerca da tolerância: Segundo tratado sobre o governo; Ensaio acerca do entendimento humano. $2^{a}$ ed. Trad. Anoar Aiex e E. Jacy Monteiro. São Paulo, SP: Abril Cultural, 1978, p. 45.

9 Para Hobbes, o direito de propriedade é objeto de pacto. Não é, pois, direito natural. Cf. HOBBES, Thomas. Leviatã ou matéria, forma e poder de um estado eclesiástico e civil. $2^{\underline{a}}$ ed. Trad. João Paulo Monteiro e Maria Beatriz Nizza da Silva. São Paulo, SP: Abril Cultural, 1979. 
$\mathrm{Na}$ interpretação de Macpherson "é preciso haver algum meio legítimo de apropriação individual, isto é, algum direito individual de apropriação" e esse direito é a propriedade sobre sua própria pessoa. ${ }^{10}$ No Segundo Tratado, lemos: "embora a terra e todas as criaturas inferiores sejam comuns a todos os homens, cada homem tem a propriedade em sua própria pessoa; e esta ninguém tem qualquer direito senão ele mesmo. $\mathrm{O}$ trabalho do seu corpo e a obra de suas mãos pode dizer-se, são propriamente dele" ${ }^{11}$ Aqui está a mais convincente justificação do direito de propriedade como direito fundamental. Violar este é violar a própria dignidade da pessoa. A propriedade de si próprio torna o resultado do meu esforço minha propriedade. A propósito, M. Merlo afirma: "a apropriação funda-se com efeito sobre a propriedade do corpo e da pessoa, ou seja, sobre o direito natural de cada um à autoconservação mediante os produtos do próprio trabalho" ${ }^{12}$ A propriedade, além de um bem, deve ser entendida "como vida, liberdade e posses" ${ }^{13} \mathrm{O}$ critério de distinção entre o privado e o comum é o esforço pelo trabalho. Dessa forma, a propriedade, como direito, não deriva do Estado. Precede qualquer constituição civil. $O$ fato de o trabalho de um indivíduo the pertencer é a justificação mais plausível do direito de propriedade ser um direito natural. A apropriação individual justifica-se pelo fato dos homens terem o direito à conservação de suas vidas e pelo fato de ser o trabalho sua propriedade. Para isso não há necessidade de consentimento alheio.

A pergunta que decorre logicamente disso refere-se aos limites da propriedade. Se o trabalho é o critério, a propriedade não deveria ser ilimitada? ${ }^{14}$ Ora, se ela é um direito natural, existe, também, um limite

${ }^{10}$ MACPHERSON, Crawford Brough. A Teoria Política do Individualismo

Possessivo: de Hobbes até Locke. Trad. Nelson Dantas. Rio de Janeiro, RJ: Paz e Terra, 1979, p. 212.

${ }^{11}$ LOCKE, John. Carta acerca da tolerância: Segundo tratado sobre o governo; Ensaio acerca do entendimento humano. $2^{a}$ ed. Trad. Anoar Aiex e E. Jacy Monteiro. São Paulo, SP: Abril Cultural, 1978, p. 45.

${ }_{12}$ MERLO, Maurizio. Poder natural, propriedade e poder político em John Locke. In: Giuseppe Duso (Org.). O Poder: História da Filosofia Política Moderna. Trad. Andrea Ciacchi e Líssia da Cruz e Silva. Petrópolis, RJ: Vozes, 2005, p. 157.

${ }^{13}$ MERLO, Maurizio. Poder natural, propriedade e poder político em John Locke. In: Giuseppe Duso (Org.). O Poder: História da Filosofia Política Moderna. Trad. Andrea Ciacchi e Líssia da Cruz e Silva. Petrópolis, RJ: Vozes, 2005, p. 157.

${ }^{14}$ Macpherson discute de modo detalhado o problema das limitações da propriedade no que chama de "limitações transcendidas" e distingue três níveis: a) a limitação do 
proposto pela própria lei da natureza, qual seja, a efetiva capacidade de usufruir do resultado produzido. $\mathrm{O}$ excedente pertence a terceiros..$^{15} \mathrm{O}$ mesmo ocorre quando o assunto é a propriedade da terra. A terra que é feita produzir pertence a quem a cultiva. ${ }^{16}$ É o trabalho que o fez merecedor. "A natureza fixou bem a medida da propriedade pela extensão do trabalho e conveniências da vida".$^{17}$ Esses são, pois, limites naturais. É claro que no transcurso histórico fatores externos alteraram esta relação propriedade/trabalho: a invenção do dinheiro foi o mais significativo. Ele permitiu um mercado de troca e a conservação e acúmulo de bens. Mas é importante registrar que ele foi objeto de "tácito acordo dos homens". A ampliação das posses e o direito sobre elas contaram com o consentimento de todos, ainda que não precisasse. $\mathrm{O}$ esforço e o mérito passaram a ser mais valorizados.

$\mathrm{O}$ estabelecimento de limites à propriedade pela capacidade de fruição poderia indicar, já em Locke, uma certa função social da

desperdício; b) a limitação da suficiência; c) a suposta limitação de trabalho. MACPHERSON, Crawford Brough. A Teoria Política do Individualismo Possessivo: de Hobbes até Locke. Trad. Nelson Dantas. Rio de Janeiro, RJ: Paz e Terra, 1979, p. 214. Mostra, sobretudo, como, com "a adoção do dinheiro", estas limitações podem ser consideradas superadas, o que torna a propriedade um direito ilimitado.

${ }^{15}$ LOCKE, John. Carta acerca da tolerância: Segundo tratado sobre o governo; Ensaio acerca do entendimento humano. $2^{\mathrm{a}}$ ed. Trad. Anoar Aiex e E. Jacy Monteiro. São Paulo, SP: Abril Cultural, 1978, p. 47.

${ }^{16} \mathrm{O}$ primeiro contratualista a defender uma posição contrária da de Locke foi J. J. Rousseau, em seu livro Discurso sobre a Origem e os Fundamentos da Desigualdade entre os Homens. Nesta obra, aponta a propriedade privada como a causadora da desigualdade entre os homens. É conhecida a sua passagem, no início da segunda parte do referido texto, onde se refere ao "verdadeiro fundador da Sociedade Civil" como aquele que cercou um terreno e afirmou ser dele. "Crimes, Guerras" e "misérias" ter-se-iam evitado se as estacas tivessem sido arrancadas e jogadas no "fosso". Cf. ROUSSEAU, Jean-Jacques. Do Contrato Social; Ensaio sobre a Origem das Línguas; Discurso sobre a Origem e os Fundamentos da Desigualdade entre os Homens; Discurso sobre as Ciências e as Artes. $2^{a}$ ed. Trad. Lourdes Santos Machado. São Paulo, SP: Abril Cultural, 1978, p. 259. Como, no entanto, o objetivo do presente artigo é o de justificar o direito de propriedade como direito fundamental e relacioná-lo com a justiça, os opositores desse direito, tais como Rousseau, Marx e outros, não foram analisados e serão objeto de artigo específico.

${ }^{17}$ LOCKE, John. Carta acerca da tolerância: Segundo tratado sobre o governo; Ensaio acerca do entendimento humano. $2^{\mathrm{a}}$ ed. Trad. Anoar Aiex e E. Jacy Monteiro. São Paulo, SP: Abril Cultural, 1978, p. 48. 
propriedade. Terras improdutivas pertencem a terceiros, a fim de que efetivem seu direito natural. É claro que a grande dificuldade é estabelecer os índices de produtividade. Mas o princípio motivador e fundamentador está expresso no Segundo Tratado sobre o Governo Civil. ${ }^{18} \mathrm{O}$ uso do dinheiro, no entanto, parece minimizar a função social da propriedade, uma vez que permite troca, acúmulo, etc.

O importante é que pelo uso do dinheiro não se feriu o princípio do trabalho como fundamento da propriedade, mas antes se fortaleceu. $\mathrm{O}$ aumento da quantidade de propriedade (propriedade da terra, por exemplo) pelo trabalho e o consequente cuidado para que nada se estrague representa uma contribuição para o aumento das reservas da humanidade. Terras produtivas não podem ser limitadas em sua extensão. $\mathrm{O}$ cuidado e o zelo pela produção, ainda que trocada por dinheiro ou bens não perecíveis, constituem mérito e "direito peculiar" de quem assim procedeu. Tudo isso está justificado a partir da tese de que o homem é "senhor de si próprio e proprietário de sua pessoa e das ações ou do trabalho que executa". Tem, pois, "em si mesmo a base da propriedade".${ }^{19}$ Com isso, está, de certa forma, justificada a apropriação ilimitada. Com o uso do dinheiro, os limites naturais deixam de existir. Dessa forma, o direito de propriedade é um direito fundamental inviolável. Faz parte do que Rawls chama do conjunto dos "elementos constitucionais essenciais". ${ }^{\prime 20}$

É nesse contexto que precisa ser situado e entendido o binômio valor/trabalho. No desenvolvimento do capitalismo posterior a Locke, outros fatores se somaram ao trabalho para determinar o valor, mas as bases foram lançadas pelo filósofo inglês. ${ }^{21}$ No entanto, o "melhoramento pelo trabalho" constitui fator decisivo na composição daquele binômio. (Pesquisas dão conta de que os índices de produtividade nos Estados Unidos são seis vezes maiores do que no Brasil).

${ }^{18}$ LOCKE, John. Carta acerca da tolerância: Segundo tratado sobre o governo; Ensaio acerca do entendimento humano. $2^{\mathrm{a}} \mathrm{ed}$. Trad. Anoar Aiex e E. Jacy Monteiro. São Paulo, SP: Abril Cultural, 1978.

${ }^{19}$ LOCKE, John. Carta acerca da tolerância: Segundo tratado sobre o governo; Ensaio acerca do entendimento humano. $2^{\underline{a}}$ ed. Trad. Anoar Aiex e E. Jacy Monteiro. São Paulo, SP: Abril Cultural, 1978, p. 51.

${ }^{20}$ RAWLS, John. Political Liberalism. New York, NY: Columbia University Press, 2005, p. 227.

${ }^{21}$ Macpherson explora essa tese, obviamente, para criticar Locke. Cf. MACPHERSON, Crawford Brough. A Teoria Política do Individualismo Possessivo: de Hobbes até Locke. Trad. Nelson Dantas. Rio de Janeiro, RJ: Paz e Terra, 1979. 
Está, pois, plenamente justificado o direito de propriedade. O direito é natural, mas sua efetivação depende do trabalho. É este, portanto, que justifica aquele direito.

\section{Direito De PropriedAde E Liberdade (HEGEL)}

Em Hegel, o direito de propriedade aparece como um dos direitos mais imediatos de concretização da ideia da liberdade. Sua Filosofia do Direito é uma demonstração inequívoca da efetivação de uma conquista da história: o princípio universal da liberdade que haverá de orientar todas as estruturas jurídicas e sociais. Ora, se a ciência do direito tem a liberdade como pressuposta (e isso aparece claramente no segundo parágrafo da introdução), cabe a "ciência filosófica do direito" indicar suas formas de concretização. ${ }^{22}$ A vontade livre é o princípio a ser realizado pelo direito e, conforme anuncia no parágrafo 4 da Filosofia do Direito, "o sistema do direito é o reino da liberdade realizada". ${ }^{23} \mathrm{~A}$ pessoa do direito, enquanto capacidade legal, é o ponto de partida. Ser pessoa de direito significa ter competência para a titularidade de direitos. $O$ direito abstrato, primeira figura da Filosofia do Direito, trata, pois, das formas mais imediatas ou dos direitos mais imediatos da pessoa do direito, enquanto sujeito de direitos. Ou seja, trata da estrutura racional das formas imediatas da vontade livre, no nível das instituições jurídicas e sociais.

A questão que, então, se impõe é esta: quais são as formas de concretização da ideia de liberdade ou da vontade livre? É exatamente aí que entra o direito de propriedade. A forma mais originária mediante a qual esse direito se efetiva ou efetiva a capacidade legal da pessoa é a posse, donde decorre o direito de uso. É pela posse que a pessoa se dirige ao mundo, como expressão de sua liberdade e com o intuito de satisfazer

${ }^{22}$ A introdução da Filosofia do Direito é a mais inequívoca exposição desse propósito. Cf. HEGEL, Georg W. F. Grundlinien der Philosophie des Rechts oder Naturrecht und Staatswissenschaft im Grundrisse: mit Hegels eigenhändigen Notizen und mündlichen Zusatzen. Frankfurt am Main: Suhrkamp, 1986 (Rph §21-30). Sobre o assunto, ver também ROSENFIELD, Denis. Política e Liberdade em Hegel. São Paulo, SP: Brasiliense, 1983 e DOTTI, Jorge Eugenio. Dialectica y Derecho: el proyecto éticopolítico hegeliano. Buenos Aires: Hachette, 1983, entre outros.

${ }^{23}$ HEGEL, Georg W. F. Grundlinien der Philosophie des Rechts oder Naturrecht und Staatswissenschaft im Grundrisse: mit Hegels eigenhändigen Notizen und mündlichen Zusätzen. Frankfurt am Main: Suhrkamp, 1986. 
suas necessidades e desejos. "A pessoa deve dar-se uma esfera externa de sua liberdade, para que exista como ideia", sustenta Hegel. ${ }^{24} \mathrm{O}$ direito de uso, decorrente da posse, é a forma mediante a qual a pessoa concretiza sua vontade livre numa realidade exterior. A posse determina a sua individualidade, mediante a apropriação das coisas do mundo. ${ }^{25}$ Ela torna o indivíduo propriamente pessoa, pois efetiva a sua capacidade jurídica. $O$ direito de posse é a primeira forma de exteriorização da liberdade. É por isso que o autor fala em "direito de apropriação" de todas as coisas. A ideia de pessoa de direito inclui necessariamente o direito de apropriação. O indivíduo se afirma como pessoa afirmando sua vontade autônoma, expressa no direito de uso. A indeterminação da ideia da liberdade adquire uma primeira determinação nesse direito. Negar o direito de propriedade significa negar a própria capacidade jurídica da "pessoa de direito". Violar esse direito é violar o direito à dignidade, pois a propriedade é a expressão da vontade racional e autônoma da pessoa. $\mathrm{O}$ exercício do direito de propriedade é o ponto de partida da libertação do "sofrimento de indeterminação" ${ }^{26}$

No entanto, a posse é insuficiente para constituir o direito de propriedade. Esta requer o reconhecimento de outras vontades. A propriedade, enquanto posse reconhecida, inclui um outro direito constitutivo do direito de propriedade: o direito de troca. Pode-se, então, falar em "propriedade plena e livre" ${ }^{27}$ Ela se constitui de uso e troca, portanto, a possível decisão em relação as qualidades das coisas: poder usá-las ou poder trocá-las. A impossibilidade de tornar-se proprietário ou de dispor livremente de sua propriedade constitui a "alienação da personalidade" ${ }^{28}$

É importante salientar que Hegel consagra o direito de propriedade

${ }^{24}$ HEGEL, Georg W. F. Grundlinien der Philosophie des Rechts oder Naturrecht und Staatswissenschaft im Grundrisse: mit Hegels eigenhändigen Notizen und mündlichen Zusatzen. Frankfurt am Main: Suhrkamp, 1986, §41.

${ }_{25}$ WEBER, Thadeu. Ética e Filosofia do Direito: autonomia e dignidade da pessoa humana. Petrópolis, RJ: Vozes, 2013, p. 67.

${ }^{26}$ HONNETH, Axel. Sofrimento de Indeterminação: Uma reatualização da Filosofia do Direito de Hegel. Trad. Rúrion Soares Melo. São Paulo, SP: Esfera Pública, 2007, p. 98.

${ }^{27}$ HEGEL, Georg W. F. Grundlinien der Philosophie des Rechts oder Naturrecht und Staatswissenschaft im Grundrisse: mit Hegels eigenhändigen Notizen und mündlichen Zusäzen. Frankfurt am Main: Suhrkamp, 1986, p. 131. ${ }_{28}$ WEBER, Thadeu. Ética e Filosofia do Direito: autonomia e dignidade da pessoa humana. Petrópolis, RJ: Vozes, 2013, p. 70. 
como primeira e imediata expressão da efetiva concretização da ideia da liberdade. O contrato é apresentado como formalização da garantia desse direito ou, como diz Marcuse, interpretando o texto hegeliano, o contrato é o instrumento que "assegura a instituição da propriedade", como decorrência do exercício do livre arbítrio. ${ }^{29} \mathrm{O}$ reconhecimento mútuo é a base de sua legitimidade. Dessa forma, o reconhecimento da propriedade, expresso no contrato, é o reconhecimento da vontade livre. Isso mostra que não há perda da extensão da liberdade, mas antes a garantia da mesma. Em seu comentário de Hegel, a propósito do reconhecimento, Valcárcel afirma: "um indivíduo só é livre, quando é reconhecido como tal e só obtém esse reconhecimento quando tem mostrado seu poder sobre as coisas exteriores, objetos de sua vontade, que pode levar à cabo uma apropriação. [...] O processo não se completa senão até que outros indivíduos consintam com essa apropriação" ${ }^{\prime \prime}{ }^{30} \mathrm{O}$ exercício da liberdade se dá por diferentes mediações. O reconhecimento da propriedade é uma delas.

Em síntese, pode-se dizer que em sendo a liberdade o princípio orientador e fundamentador das estruturas jurídicas e sociais, o direito de propriedade é a expressão mais imediata da realização daquele princípio. A pessoa de direito, enquanto capacidade legal, encontra na propriedade a efetivação dessa capacidade. Em outras palavras: a pessoa do direito como sujeito de direitos tem no direito de propriedade a sua realização. Violar esse direito significa violar a própria pessoa de direito, em sua liberdade e dignidade, ou seja, significa negar um dos direitos de personalidade.

\section{Direito de Propriedade e Justiça (RAWls)}

O direito de propriedade está expressamente contemplado na formulação e explicitação do primeiro princípio de justiça de Rawls. Faz parte da lista de direitos fundamentais enumerados. No Liberalismo Político, assim se expressa: "entre as liberdades fundamentais da pessoa, está o direito de adquirir e ter o uso exclusivo da propriedade pessoal" ${ }^{31}$

${ }^{29}$ MARCUSE, H. Razão e Revolução: Hegel e o advento da teoria social. $2^{\mathrm{a}}$ ed. Trad. Marilia Barroso. Rio de Janeiro, RJ: Paz e Terra, 1978, p. 184.

30 VALCÁRCEL, Amelia. Hegel y la Ética: sobre la superación de la "mera moral". Barcelona: Anthropos, 1988, p. 331.

${ }^{31}$ RAWLS, John. Political Liberalism. New York, NY: Columbia University Press, 2005, p. 298.

2 JOURNAL OF INSTITUTIONAL STUDIES 2 (2016) 
Esse direito encontra sua justificação no acordo das partes na posição original. Faz parte, portanto, dos "elementos constitucionais essenciais" em torno dos quais o acordo é possível e necessário. É sabido que o autor defende uma concepção política de justiça, isto é, "elaborada para um tipo específico de objetivo, qual seja, para instituições políticas, sociais e econômicas", o que chama de "estrutura básica da sociedade". ${ }^{32}$ Além disso, ela não deriva de nenhuma doutrina moral abrangente. Goza, pois, de autossustentabilidade. Isso significa que não se pode recorrer a valores éticos ou religiosos para justificar os direitos fundamentais. Não haveria acordo. Isso só é possível com os valores políticos. É o caso do direito de propriedade. A sua justificação como valor político é a condição de possibilidade de um acordo como elemento constitucional essencial. $\mathrm{O}$ estabelecimento dessas prioridades deve-se à efetiva possibilidade de sua proteção.

E importante salientar que o direito de propriedade ou o que Rawls chama de "direito de adquirir e ter o uso exclusivo da propriedade pessoal", consta da lista de liberdades fundamentais "verdadeiramente essenciais" para o desenvolvimento dos cidadãos. ${ }^{33} \mathrm{O}$ estabelecimento dessas prioridades deve-se à efetiva possibilidade de sua proteção.

Mas como o autor elabora a lista de direitos e liberdades fundamentais especificados no primeiro princípio de justiça? A resposta encontramos no Liberalismo Político e em Justiça como Equidade: Uma Reformulação. ${ }^{34}$ Há duas maneiras de fazê-lo: a primeira é histórica e a segunda é analítica. Quanto à primeira, é preciso examinar os regimes democráticos mais bem-sucedidos e identificar os direitos e liberdades protegidos. O direito de propriedade, sem dúvida, estará entre eles. Certamente haverá uma grande semelhança com a lista apresentada por Rawls. A segunda envolve a concepção normativa de pessoa. Quais são os direitos fundamentais necessários para viabilizar o pleno exercício de suas qualidades morais, isto é, o senso de justiça e a concepção do bem? Que direitos precisam ser protegidos para o desenvolvimento dessas qualidades dos cidadãos? $\mathrm{O}$ direito de propriedade é um dos que

${ }^{32}$ RAWLS, John. Political Liberalism. New York, NY: Columbia University Press, 2005, p. 11.

${ }^{33}$ RAWLS, John. Political Liberalism. New York, NY: Columbia University Press, 2005, p. 298.

${ }^{34}$ Cf. RAWLS, John. O Liberalismo Político. Trad. Álvaro de Vita. São Paulo, SP: WMF Martins Fontes, 2011; e RAWLS, John. Justiça como Equidade: uma reformulação. Org. Erin Kelly. Trad. Cláudia Berliner. São Paulo, SP: Martins Fontes, 2002. 
compõem a lista dos direitos enumerados. ${ }^{35}$

Percebe-se que os direitos fundamentais têm, pois, uma dupla justificação: o sucesso histórico e o atendimento da efetivação das qualidades morais. $\mathrm{O}$ fundamental é perceber que as pessoas enquanto livres e iguais, investidas do "véu da ignorância", concordariam sobre o estabelecimento do direito de propriedade no rol dos direitos e liberdades básicos. Isto porque, primeiro, consta da lista de direitos fundamentais contemplados pelas constituições democráticas mais bem-sucedidas e, segundo, porque é condição indispensável para a realização das qualidades morais dos cidadãos e o exercício pleno da cidadania. Não se desenvolve o senso de justiça e uma concepção do bem sem a garantia de certos direitos fundamentais, entre os quais é fundamental o direito de propriedade. Ele é inerente a concepção normativa de pessoa. O que está em jogo é a satisfação das necessidades básicas dos cidadãos, condição para o exercício dos demais direitos fundamentais. Dessa forma, o direito de propriedade é uma espécie de carro chefe dos direitos fundamentais. Sem efetivação dele, falta a base para satisfação das necessidades básicas dos cidadãos. Falta o componente indispensável que compõe o conteúdo do mínimo existencial. Este é o significado da referência a um "princípio lexicamente anterior" ao primeiro princípio de justiça. ${ }^{36}$

Mas o que se deve entender especificamente pelo direito de propriedade? Qual é o seu alcance? Se entre os direitos e liberdades fundamentais da pessoa está "o direito de adquirir e ter o uso exclusivo da propriedade pessoal", qual é a função desse direito para o exercício pleno da cidadania, ou seja, para a realização política da pessoa e qual é propriamente o seu conteúdo? Para o autor, o objetivo é "permitir uma base material suficiente para haver um sentimento de independência pessoal e autorrespeito, ambos essenciais para o desenvolvimento e exercício das capacidades morais" ${ }^{37} \mathrm{O}$ autor refere, inclusive, "as bases sociais do autorrespeito". Ter e desenvolver senso de justiça e ter e desenvolver uma concepção do bem requer um sentimento de autorrespeito, proporcionado pelo direito de propriedade, efetivamente assegurado e concretizado. $\mathrm{O}$ autorrespeito faz parte da lista dos bens primários, fundamentais para o exercício pleno da cidadania, uma

${ }^{35}$ RAWLS, John. Political Liberalism. New York, NY: Columbia University Press, 2005, p. 298; e WEBER, Thadeu. Ética e Filosofia do Direito: autonomia e dignidade da pessoa humana. Petrópolis, RJ: Vozes, 2013, p. 149.

${ }^{36}$ RAWLS, John. Political Liberalism. New York, NY: Columbia University Press, 2005, p. 7.

${ }^{37}$ RAWLS, John. Political Liberalism. New York, NY: Columbia University Press, 2005, p. 298. 
espécie de mínimo existencial em sentido amplo. É por isso que se constitui num elemento constitucional essencial.

Há que se enfatizar que, ao fazer parte da lista dos bens primários, o direito de propriedade é condição do exercício da cidadania e não só elemento constitutivo do mínimo existencial em sentido estrito, isto é, da satisfação das necessidades básicas para uma vida digna. Rawls está se referindo "às necessidades das pessoas em sua condição de cidadãos", isto é, como livres e iguais, e não só à sua condição de seres humanos. ${ }^{38} \mathrm{O}$ sentimento de independência e, por conseguinte, de autonomia, está diretamente ligado à possibilidade de efetivação do direito de propriedade. Em síntese: O desenvolvimento da concepção normativa de pessoa e o exercício pleno da cidadania requer o direito de propriedade assegurado.

No entanto, Rawls limita esse conceito de propriedade excluindo "duas concepções mais abrangentes". $\mathrm{O}$ "direito de herança" e "o direito de possuir meios de produção e recursos naturais" são excluídos desse direito de propriedade. Esses direitos, segundo o autor, "não são necessários para o desenvolvimento e exercício das capacidades morais". ${ }^{39}$ Isso não significa que não possam ser contemplados. Sua avaliação deve ser feita nos estágios posteriores, como, por exemplo, no estágio legislativo, tendo em vista circunstâncias específicas e aspectos históricos particulares de uma determinada sociedade. Mas eles não constituem elementos constitucionais essenciais. Sobre o direito de herança e sobre o direito de controlar os meios de produção, há muita controvérsia e dificilmente haverá acordo. ${ }^{40}$ Devem, portanto, ficar fora da agenda política. Além do mais, não são indispensáveis para a realização das qualidades morais das pessoas, ou seja, da concepção política de pessoa. $\mathrm{O}$ exercício pleno de cidadania inclui o direito de propriedade, mas não necessariamente o direito de herança e o do controle dos meios de produção. A indicação das "bases sociais do

${ }^{38}$ RAWLS, John. Political Liberalism. New York, NY: Columbia University Press, 2005, p. 179.

${ }^{39}$ RAWLS, John. Political Liberalism. New York, NY: Columbia University Press, 2005, p. 298.

40 Sobre o tema da propriedade e os meios de produção e o sistema de mercados, ver RAWLS, John. A Theory of Justice. Cambridge, MA: Harvard University Press. 1971, p. 270 e ss. Rawls aponta a principal diferença entre uma economia de propriedade privada e o socialismo, no referente ao setor público. Também mostra como um sistema de mercados é consistente com seus princípios de justiça, ou seja, com as liberdades iguais e a igualdade equitativa de oportunidades. 
autorrespeito", como bem primário, dá bem a ideia de que a propriedade dos meios de produção é de direito público. É fundamental perceber que a concepção normativa de pessoa requer a garantia de certos direitos e liberdades para a sua efetiva realização. O direito de propriedade é sempre lembrado e deve ser assegurado.

A delimitação do seu conteúdo, no entanto, deve-se ao fato da necessidade de se estabelecer prioridades tendo em vista possíveis conflitos com outras liberdades. Rawls limita os direitos fundamentais àqueles "verdadeiramente essenciais" a fim de efetivamente garantir a sua proteção. É o caso do direito de propriedade, nos termos definidos acima. Ele é um direito essencial para a realização da concepção política de pessoa. Para obter um acordo em torno dele, e poder assegurá-lo, os aspectos controvertidos devem ser retirados da agenda política.

\section{CONSIDERAÇÕES FINAIS: o Direito de Propriedade e JustiçA}

A análise dos três autores indica claramente o direito de propriedade como direito fundamental de todo cidadão. Seja vinculado ao trabalho, seja uma forma de concretização da ideia de liberdade, seja como conquista da história, ou seja enumerado no rol dos direitos que compõem os princípios de justiça, ele é, efetivamente, um elemento constitucional essencial. Estados democráticos de direito não podem ignorá-lo.

A tese de que o trabalho é o fundamento do direito de propriedade valoriza o esforço e o mérito, indispensáveis para a organização de uma sociedade justa. $\mathrm{O}$ fato de ser um direito natural não o torna imune às flutuações do mercado e dos interesses ideológicos de certas corporações, mas o garante como direito fundamental que nem mesmo o contrato social pode desconhecer. Dessa forma, pode-se endossar a tese de JeanPhilippe Lévy, segundo a qual a propriedade responde "a uma das necessidades da natureza humana". Ela representa "o último refúgio capaz de garantir a segurança e a liberdade" ${ }^{41}$ Macpherson, referindo-se à "contribuição de Locke", afirma ser "a teoria da propriedade uma justificação do direito natural, não apenas à propriedade desigual, mas a

${ }^{41}$ LÉVY, Jean-Philippe. História da Propriedade. Trad. Fernando Guerreiro. Lisboa: Editorial Estampa, 1973, p. 151.

2 JOURNAL OF INSTITUTIONAL STUDIES 2 (2016) 
uma apropriação individual ilimitada". ${ }^{42}$ A justificação estaria no fato de o trabalho do indivíduo lhe pertencer. Daí a qualificação de "individualismo possessivo". Ignora, no entanto, o autor, que trabalho é mérito e esforço e que precisa ser valorizado, por questões de justiça.

Tomar como ponto de partida de justificação o direito de propriedade a propriedade da própria pessoa é associá-la à inviolabilidade de sua dignidade. Uma Constituição justa, que tem a dignidade como um dos seus fundamentos, haverá de garantir o direito de propriedade como constitutivo de seu conteúdo e como uma de suas formas de concretização. Caso contrário, a dignidade torna-se uma palavra vazia. A base do pensamento liberal está posta.

Justificar o direito de propriedade pela ideia da liberdade como conquista da história é apontar outro critério que não a exclusividade da autoridade da razão kantiana. Justificá-lo como expressão da liberdade é dar-lhe o caráter de inviolabilidade.

É significativo o avanço de Rawls no sentido de estabelecer, através do anúncio dos princípios de justiça, sobretudo o primeiro, a necessidade de "satisfação das necessidades básicas dos cidadãos" para uma vida digna, exigência esta imposta pelo próprio exercício dos direitos fundamentais, mormente o direito de propriedade. ${ }^{43}$ Este direito é, pois, componente do "princípio lexicamente anterior" ao primeiro princípio (o dos direitos e liberdades básicos) ${ }^{44}$, na medida em que é parte do conteúdo do mínimo existencial necessário para o exercício desses direitos. A importância do direito de propriedade está no fato de fazer parte de um conjunto de direitos que têm prioridade sobre o segundo princípio, ou seja, o que trata das desigualdades sociais e econômicas. $\mathrm{O}$ estabelecimento dessa prioridade dos direitos fundamentais lhes dá o status de inviolabilidade, uma vez que constituem o conteúdo base da dignidade da pessoa humana. Não podem, pois, ser restringidos em nome de vantagens econômicas. A capacidade de serem membros cooperativos da sociedade e de poderem desenvolver o senso de justiça e uma concepção do bem requer que os cidadãos tenham seus direitos fundamentais assegurados. O direito de propriedade é decisivo,

${ }^{42}$ MACPHERSON, Crawford Brough. A Teoria Política do Individualismo

Possessivo: de Hobbes até Locke. Trad. Nelson Dantas. Rio de Janeiro, RJ: Paz e Terra, 1979, p. 233.

${ }^{43}$ RAWLS, John. Political Liberalism. New York, NY: Columbia University Press, 2005, p. 7.

${ }^{44}$ RAWLS, John. Political Liberalism. New York, NY: Columbia University Press, 2005, p. 7. 
sobretudo no atendimento das condições materiais básicas para uma vida digna. Uma sociedade justa, fundada na dignidade, deverá apresentar garantias daquele direito como forma de concretização desta.

O que fica claro é que a motivação da instituição do Estado e sua manutenção quase sempre esteve ligado, e continua assim, à proteção do direito de propriedade. Trata-se, pois, de uma conquista irreversível e inviolável da história. Assegurar a propriedade dos indivíduos e dar-lhes as garantias do seu devido uso é a função fundamental do Estado. Isso está claro em Locke, faz parte da concretização da liberdade em Hegel e é componente constitutivo do mínimo existencial em Rawls. Assim, pois, os princípios de justiça, que orientam as principais estruturas jurídicas e sociais, devem contemplar, dentro de um conjunto de direitos fundamentais, o direito de propriedade. Isto inclui sua função social. Trata-se de um elemento constitucional essencial. Nenhum Estado Democrático de Direito pode ignorá-lo.

\section{REFERÊNCIAS}

DOTTI, Jorge Eugenio. Dialectica y Derecho: el proyecto ético-político hegeliano. Buenos Aires: Hachette, 1983.

HEGEL, Georg W. F. Grundlinien der Philosophie des Rechts oder Naturrecht und Staatswissenschaft im Grundrisse: mit Hegels eigenhändigen Notizen und mündlichen Zusatzen. Frankfurt am Main: Suhrkamp, 1986.

HOBBES, Thomas. Leviatã ou matéria, forma e poder de um estado eclesiástico e civil. $2^{a}$ ed. Trad. João Paulo Monteiro e Maria Beatriz Nizza da Silva. São Paulo, SP: Abril Cultural, 1979.

HONNETH, Axel. Sofrimento de Indeterminação: Uma reatualização da Filosofia do Direito de Hegel. Trad. Rúrion Soares Melo. São Paulo, SP: Esfera Pública, 2007. 
LÉVY, Jean-Philippe. História da Propriedade. Trad. Fernando Guerreiro. Lisboa: Editorial Estampa, 1973.

LOCKE, John. Carta acerca da tolerância: Segundo tratado sobre o governo; Ensaio acerca do entendimento humano. $2^{\underline{a}}$ ed. Trad. Anoar Aiex e E. Jacy Monteiro. São Paulo, SP: Abril Cultural, 1978.

MACPHERSON, Crawford Brough. A Teoria Política do Individualismo Possessivo: de Hobbes até Locke. Trad. Nelson Dantas. Rio de Janeiro, RJ: Paz e Terra, 1979.

MARCUSE, H. Razão e Revolução: Hegel e o advento da teoria social. $2^{\underline{a}}$ ed. Trad. Marilia Barroso. Rio de Janeiro, RJ: Paz e Terra, 1978.

MERLO, Maurizio. Poder natural, propriedade e poder político em John Locke. In: Giuseppe Duso (Org.). O Poder: História da Filosofia Política Moderna. Trad. Andrea Ciacchi e Líssia da Cruz e Silva. Petrópolis, RJ: Vozes, 2005.

PROUDHON, Pierre-Joseph. O que é a propriedade? Lisboa: Editorial Estampa, 1971.

RAWLS, John. O Liberalismo Político. Trad. Álvaro de Vita. São Paulo, SP: WMF Martins Fontes, 2011.

A Theory of Justice. Cambridge, MA: Harvard University Press. 1971.

. Political Liberalism. New York, NY: Columbia University Press, 2005.

. Justiça como Equidade: uma reformulação. Org. Erin Kelly. Trad. Cláudia Berliner. São Paulo, SP: Martins Fontes, 2003. 
ROSENFIELD, Denis. Política e Liberdade em Hegel. São Paulo, SP:

Brasiliense, 1983.

ROUSSEAU, Jean-Jacques. Do Contrato Social; Ensaio sobre a Origem das Línguas; Discurso sobre a Origem e os Fundamentos da Desigualdade entre os Homens; Discurso sobre as Ciências e as Artes. $2^{\underline{a}}$ ed. Trad. Lourdes Santos Machado. São Paulo, SP: Abril Cultural, 1978.

VALCÁRCEL, Amelia. Hegel y la Ética: sobre la superación de la “mera moral". Barcelona: Anthropos, 1988.

WEBER, Thadeu. Ética e Filosofia do Direito: autonomia e dignidade da pessoa humana. Petrópolis, RJ: Vozes, 2013.

O Direito de Propriedade e Justiça

The Property Right and Justice Submetido em: 2016-11-07 Aceito em: 2017-01-30 